\title{
TIPOGRAFIA E DESIGN NA CONSTRUÇÃO DA LINGUAGEM VISUAL DA LETRA
}

Marcelo José da Mota

Universidade do Oeste Paulista - UNOESTE

marcelomota@unoeste.br

Mariangela Fazano Amendola

Universidade do Oeste Paulista - UNOESTE

mariangelafazano@gmail.com

Resumo: Este artigo propõe resgatar a história do surgimento da escrita e sua influência na construção da informação visual ao relacionar padrões visuais às características tipográficas de comunicação. Pretende-se, com este estudo, fomentar a importância e o papel da tipografia, considerando seus aspectos físicos e sensoriais do processo interativo do homem com as letras. A metodologia proposta trata dos princípios da criação tipográfica, de classificações, de famílias, da geometria na construção do tipo e da informação visual na representação do texto verbal e não-verbal de uma peça de design. O estudo mostra a importância do design e de padrões evolutivos da representação gráfica no processo de criação com tipos.

Palavras-chave: tipografia; design gráfico; escrita.

\begin{abstract}
This article considers to rescue the history of the sprouting of the writing and its influence in the construction of the visual information when relating visual standards to the typographical features of communication. It is intended, with this study, to foment the importance and the paper of the typography, considering its physical and sensorial aspects of the interactive process of the man with the letters. As methodology, it was used of the principles of the typographical creation, sortings, families, geometry in the construction of the type and the visual information in the representation of the verbal and not verbal. The study it shows the importance of design and evolutivos standards of the graphical representation in the process of creation with types.
\end{abstract}

Keywords: typography; graphic design; writing 


\section{INTRODUÇÃO}

A principal característica biológica do ser humano e que o diferencia de outras espécies, é sua capacidade de estabelecer relacionamentos entre múltiplos eventos que ocorrem. Ostrower (1997) explica que o criar e o formar dão-se nos processos comunicacionais necessários para gerar significados as coisas, como forma de interpretar fenômenos. O reconhecimento e a manipulação de códigos simbólicos pelo homem, somente é possível pela ordenação e orientação de tais fenômenos individualmente associadas a memória e a inteligência da percepção. Para a autora, a criação gráfica parte de um caminho evolutivo da inteligência discursiva do homem em ser consciente, ser sensível e ser cultural. Padrões históricos e modelos do ser social representados na sua forma ou contexto, realizam-se sempre e unicamente dentro de formas culturais traduzidas para o cotidiano de sinais e de símbolos, o que faz possível a elaboração de novas atitudes e de novos comportamentos para uma possível criação. A composição criativa é um resgate aos significados atribuídos as mais diferentes maneiras de se comunicar algo dentro de um limite e de um princípio dialético. A tipografia é traduzida com a expressão máxima do pensamento, da técnica verbal e da não-verbal que, por associações geométricas e imagens gráficas, consegue expressar diversos sentimentos e anseios do ser social.

Com este artigo pretende-se resgatar no tempo, a evolução da imagem tipográfica e o desenvolvimento de padrões geométricos na projetação com tipos e seu objetivo é fomentar a importância da linguagem visual funcional aplicada no contexto visual determinado.

\section{EVOLUÇÃO GRÁFICA DOS TIPOS}

Os tipos gráficos aparecem com a invenção da escrita derivada de diferentes regiões do mundo, no desenvolvimento independente de várias formas de representação da fala, em um período de tempo indeterminado. Há milênios, anteriores a era cristã, já havia tecnologia de construção tipográfica empregada para comunicar uma ideia ou o pensamento. A geometria aplicada na construção e na visualização de símbolos para codificar uma ideia, uma ação ou pensamento de antigas civilizações, contribuíram para os princípios básicos da formação e composição dos desenhos tipográficos contemporâneos. Alguns exemplos antigos podem ser observados na criação de padrões visuais, como a escrita dos egípcios, com sua escrita pictórica; como da região da mesopotâmia, com a escrita cuneiforme, gravações em forma de cunha em lâminas de barro; como dos chineses, com a escrita de natureza técnica ideográfica e repleta de significados, como dos maias na península do lucatão, com a simplicidade e a pureza das formas geométricas que representavam seus deuses (DEFLEUR; BALL-ROKEACH, 1993). Composto por criações harmoniosas e equilibradas, o alfabeto grego foi adaptado pelos romanos na Itália devido a necessidades do latim. O conhecimento e a cultura foram rapidamente difundidos pela escrita, que com características romanas foi adotada em toda a Europa e em outras regiões do mundo. O marco para a escrita ocidental é a normalização, em 789 DC, que estabeleceu os padrões da escrita dos tipos conhecido como carolíngea, por Carlos Magno, o então primeiro governante do Sacro Romano (NIEMEYER, 2006). Dentre os padrões estabelecidos por Magno, estavam diferenciações entre caixa alta e baixa, assim como o uso de espaços brancos entre as letras e palavras até hoje utilizados. 
"Nas antigas sociedades, até o século XV, era mais evidente a exploração de imagens e rituais devido aos índices de analfabetismo altos. Neste período o que não podia ser anotado devia ser lembrado, e o que devia ser lembrado devia ser apresentado de maneira fácil de se apreender(BIGGS; BURKE, 2006, p. 19)". Com influências anteriores da técnica de representação visual neste mesmo período de transição social, os rituais se transformaram em oportunidades para a transmissão de fatos e expressão poética. Um exemplo são as tapeçarias do Ocidente (Grã-Bretanha) e do Oriente (Pérsia) entre os séculos X e XIV com as ilustrações de fábulas e histórias estampadas com uma narrativa visual. Os exemplos da figura 1 explicam a utilização dos tipos gráficos e ilustrações cenográficas para expressar os conteúdos informacionais ordenados em significados e signos visuais.
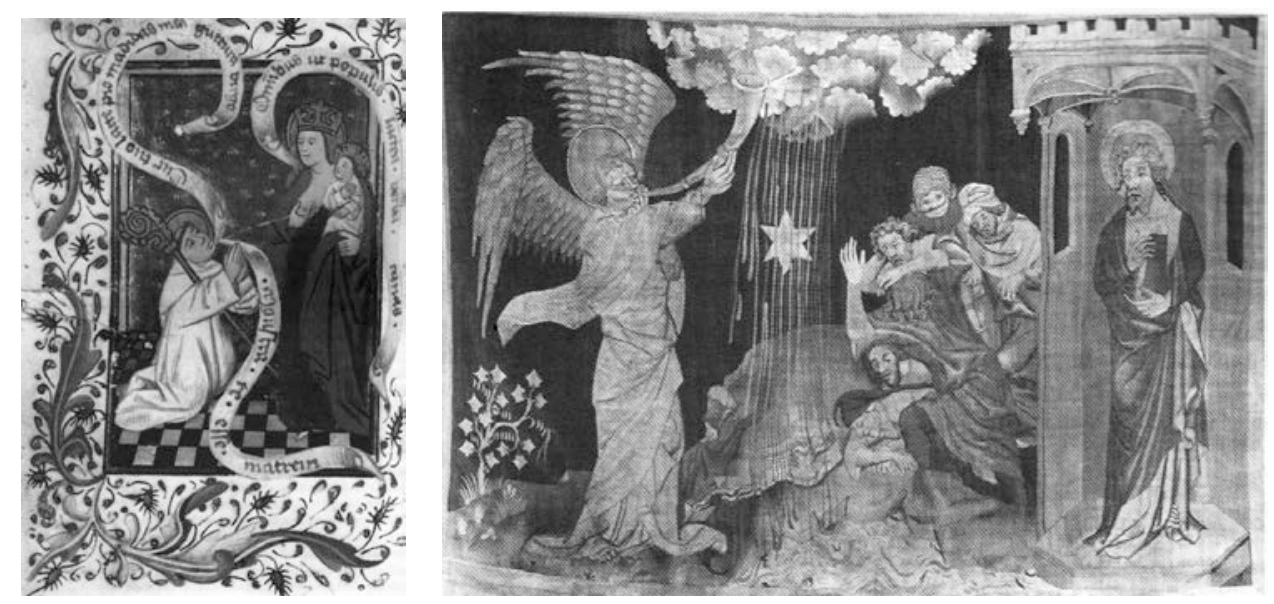

Figura 1: Na primeira imagem, uma página do Livro das Horas de 1470 e na segunda imagem, tapeçaria Apocalipse do século XIV.

Fonte: Briggs e Burke (2006, p. 13-19).

Muitas outras manifestações sociais antigas de caráter informativo e em diferentes partes do mundo, influenciaram os procedimentos de produção tipográfica e leituras contemporâneas das letras. Os autores Briggs e Burke (2006) relatam tais representações ou manifestações populares como sendo importantes para a construção de um universo literário contemporâneo. Também afirmam que tais imagens evoluíram para os quadrinhos e para as artes gráficas.

Ao final da Idade Média, século XV, a escrita já se tornara quotidiana com a produção de livros feitos pelos copistas, assim chamados os monges que desenhavam cada exemplar nos mosteiros da igreja romana. A tecnologia das letras e seu papel como registro contribuíram para a configuração de experimentos gráficos visuais e a união da imagem com as palavras escritas se tornaram um salto na comunicação.

O início da era da evolução gráfica dos tipos e da comunicação visual foi a impressão, em 1456 na Alemanha, da Bíblia de Mezanino, por Johann Gutenberg, com a tecnologia dos tipos móveis em prensas primitivas de madeira. A prensa não era novidade para Gutenberg. Como já era utilizada pelos gregos para espremer uvas e outros derivados agrícolas, ele apenas aprimorou-a junto a tecnologia do papel e das tintas criando o tipo móvel fundido e os primeiros meios práticos de impressão. As duas imagens da figura 2 ilustram a evolução dos tipos e sua manipulação empregada na página entre a primeira impressão da bíblia de Gutenberg e após 45 anos com publicações mais legíveis e estruturadas no diagrama. Neste curto espaço de tempo, 
houve um aperfeiçoamento visual de letras e dos meios de impressão, bem como das técnicas matemáticas e geométricas dos processos gráficos de visualidade.

\begin{tabular}{|c|c|}
\hline \\
\hline noditt ancflyacmido & 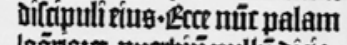 \\
\hline folbancs. eliafor ung & 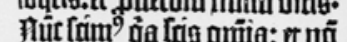 \\
\hline co vost to homtic heva & opus tet tibiut ảs te introget. \\
\hline 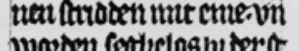 & 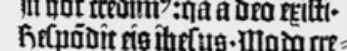 \\
\hline at erebart anemarevele & 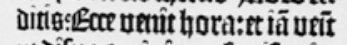 \\
\hline & 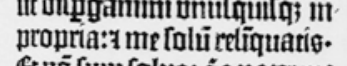 \\
\hline wile a cart vingerbaye & 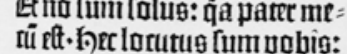 \\
\hline 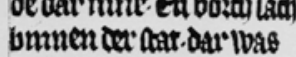 & 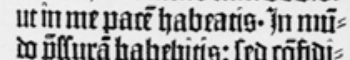 \\
\hline upe ce plaan. vos car bo: & 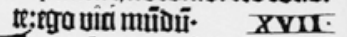 \\
\hline d) laghen axpentenalfo & ing:rt $[\mathrm{bi}=$ \\
\hline lauge- watut cectn foldá & Iruatín ofulis ĩ relü dixit- \\
\hline darto ownungen bat he & 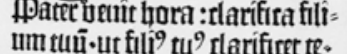 \\
\hline 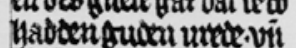 & 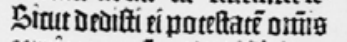 \\
\hline gutukop al cor finlant & 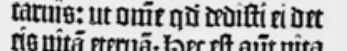 \\
\hline Goodecterd danten bo: & tcetna:ut tognóraät te folū xū \\
\hline & \\
\hline
\end{tabular}

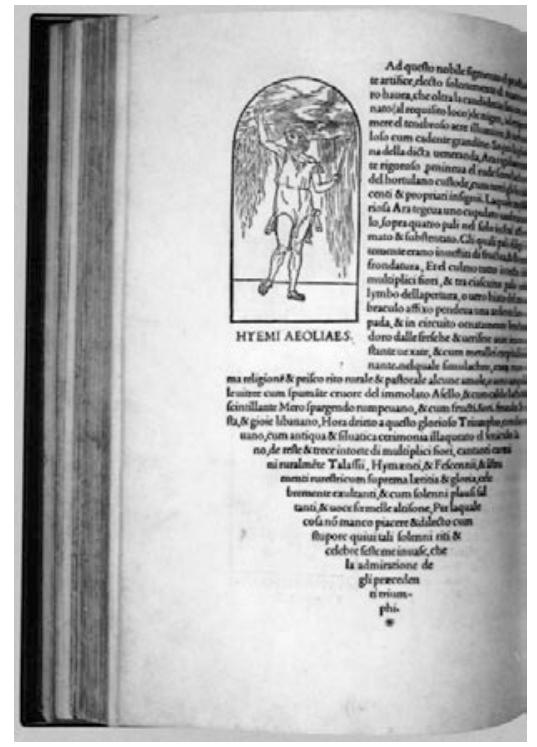

Figura 2: Detalhe da Bíblia de Mezanino impressa por Gutenberg, em 1456, e página do livro Hypnerotomachia Poliphili de Aldus Manutius, impresso em1500.

Fonte: Jury (2006, p. 34 e 35).

O progresso cultural e urbano proporcionado pela revolução das tecnologias de impressão, com a reprodução de múltiplos exemplares de documentos, periódicos e livros, agregou a educação e a cultura, acúmulo de informações de aprendizagem e de ensino. Além de contribuir com registros históricos fundamentais para a evolução científica, filosófica, política e poética da existência humana. Camargo (2003) descreve que a invenção de Gutenberg, que foi a de associar e otimizar um conjunto de sistemas, isto é a prensa e os tipos móveis, revolucionaram o progresso tecnológico com o acúmulo do conhecimento. Ainda segundo o mesmo autor:

Numa Europa [...] onde a urbanização se acentuava, o sistema produtivo prenunciava a transformação das corporações em unidades pré-industriais (das obras únicas à produção em série) e ocorreria uma enorme expansão cultural [...] a prensa de tipos móveis representou uma revolução. (CAMARGO, 2003, p. 11).

Desde então, com a evolução da palavra e da representação gráfica para personificar um sentimento ou informação, torna-se indispensável um método de criação tipográfica para as artes visuais. A dependência da originalidade e do estímulo plástico dos tipos, passa a ser fundamental para apresentar ao leitor uma identificação, uma definição e uma decisão no ato do consumo das informações.

\subsection{Classificação Tipográfica}

Tipografia é uma área científica que estuda a influência estético-formal e a funcionalidade dos tipos de letra, como afirma Jury (2006, p.12). A representação gráfica das letras produz efeitos no leitor e sua utilização pelo designer deve ser de acordo com sua estrutura técnica particular incluindo família, largura, altura, pontuação, linhas e espacejamento. Os aspectos comunicacionais dos tipos vão além da legibilidade do texto, eles conduzem e facilitam a leitura, afirma Jury (2006). O tipo 
também é um viés cognitivo que transmite clareza, suavidade, beleza e elegância. $A$ importância do uso de tipos é garantir um trabalho esteticamente agradável, com significação e de fácil usabilidade.

Jury (2006) completa que não há nenhum padrão o qual descreva precisamente o que pode constituir estruturalmente os caracteres do alfabeto, numerais e pontuações; alguns critérios serão considerados em sua formação como os relacionados ao peso e ao caráter, que ainda terão outras variações. Como exemplo pode-se considerar; estipular regras na alocação das letras e das palavras, afastamento entre linhas e caracteres que exprime uma textura mais leve do texto e uma textura densa quando mais próximo; o itálico que pode ser desenhado individualmente nos tipos, ou mesmo com o recurso opcional, mas com o efeito indicando velocidade ou aproximando-se da escrita manual; o negrito ou bold pode também ser característica do tipo ou efeito opcional e utilizado para o destaque visual.

Ribeiro (1998) afirma que a tecnologia foi importante na transformação da linguagem tipográfica, fornecendo independência e oportunidade de experimentar. No entanto, regras e convenções não mudaram; o que acontece é a constante evolução da língua falada e sua adaptação visual. Desde Gutenberg, a classificação dos tipos era feita de acordo com o nome da obra impressa ou o nome da família do impressor. Com a evolução da produção gráfica e com a Revolução Industrial, tornou-se quase impossível a catalogação dos tipos, devido a grande variedade de fontes. No início do século XX, em 1921, o gráfico francês Francis Thibaudeau, através de uma comparação geral entre os tipos, construiu uma classificação em quatro famílias básicas. $\mathrm{O}$ gráfico deteve-se a exames detalhados da serifa, da largura, da altura e da cor que deram origem a quase infinita construção de tipos, são elas: Bastão, Elzevir, Egipciana, Didot (figura 3). De construções geométricas ousadas, existem mais duas famílias, Fantasia e Bastarda, catalogadas pelo francês (RIBEIRO, 1998).

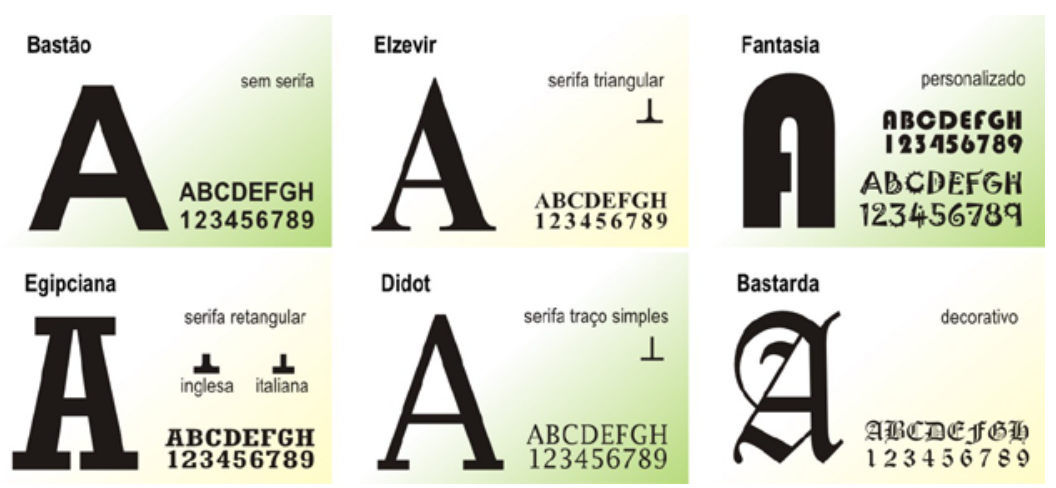

Figura 3 - Famílias dos tipos e suas características feitas por Francis Thibaudeau. Fonte: Ribeiro (1998, p. 56-62).

Thibaudeau, conforme relata Ribeiro (1998)propôs uma das mais simples maneiras de tentar identificar as famílias de tipos, mas ainda não unanime para tal sistema, muitos autores discordam entre si para classificar os tipos. O Brasil adotou esta classificação, segundo Baer (1999), mas com algumas modificações, como por exemplo, adota a divisão em romanos para as letras com serifa; egípcios e góticos para as blackletter; etruscos para as sem serifa; manuscritos e fantasia; e utiliza o termo elzeviriano como sinônimo de romano antigo. 
De acordo com Lupton (2006, p. 42) "os processos de impressão e tecnologia gráfica, no século XIX é que produziram um sistema básico de classificação de famílias tipográficas nas quais vigoram até hoje". Lupton (2006) afirma que as famílias de impressores buscavam analogias entre a história e a herança de seu ofício. Na figura 4, a autora descreve a divisão em famílias de tipos humanistas que imitam a escrita a mão; tipos transicionais e modernos sendo abstratos, menos orgânicos e respeitando a diversidade da letra. Este grupo principal de famílias foi ampliado no século XX e, desde então, são propostos esquemas mais refinados baseados em características tecnológicas, históricas e geométricas da escrita antiga.

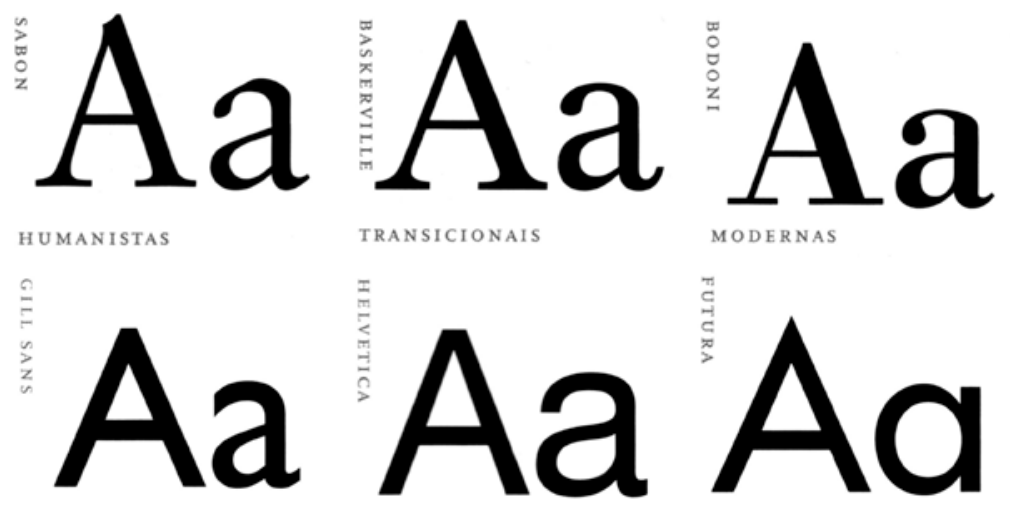

Figura 4 - Grupo principal de classificação das famílias tipográficas. Fonte: LUPTON (2006, p. 42).

O que regulamenta a tipografia quanto ao tratamento e manipulação dos tipos na composição são o conhecimento, a experiência e as limitações práticas da língua e da mídia. A equipe de trabalho necessita de normatização, classificação e medidas tipográficas impostas pelo projeto gráfico em todas as etapas de produção para o mesmo ser reconhecido e entendido pelo leitor. O contraste entre as formas e tamanhos da tipografia é que irá dividir uma página, apresentar uma informação, destacar um dado sensível, ou melhor, comunicar uma ideia. Os tipos aplicados em um suporte têm que efetivar a comunicação e estabelecer uma unidade de fácil reconhecimento do idioma e da identidade visual que é representada, além de seguir conceitos de legibilidade, acessibilidade e usabilidade.

\subsection{Padrões Visuais e Geometria}

A representação tipográfica nada mais é que um conjunto de normas e padrões estabelecidos em convenção para codificar a informação verbal. Foi estabelecido um padrão de construção de sinais que tem como característica a base geométrica na geração de partes e formas. Os padrões visuais proporcionam uniformidade e funcionalidade as letras e estão presentes no processo de criação, partindo de pressupostos e princípios simétricos ou assimétricos do desenho.

É certa a afirmação de Doczi (1990) que o limitado dá forma ao ilimitado. A Natureza e toda criação do homem estão relativamente ligadas, em perfeita harmonia com o Cosmo. Se olharmos ao nosso redor, veremos que a vida cresce ordenada por uma força invisível, mas que pode ser medida e calculada. É por meio do equilíbrio de forças, de equações logarítmicas, de fórmulas matemáticas, de formas geométricas, o 
desenvolvimento, o crescimento e a evolução de toda espécie, da fauna e da flora, constituem-se.

Dinergia é o termo encontrado para determinar a relação entre as partes. É o termo mais adequado, pois significa dois pólos ou campos de energia que sugerem a criação de uma outra nova. A união das partes exprime o poder gerador. É o que dá origem a vida, ao movimento e a toda manifestação do homem perante o seu mundo. Doczi (1990, p. 13), define dinergia como "o processo criador de energia que transforma discordâncias em harmonias, permitindo que as diferenças e os diferentes se complementem".

Pode-se dizer que há uma força dinérgica na tipografia. As construções e combinações das letras, sua representação gráfica, a geométrica de sinais e símbolos são forças espaciais da cultura que geram significação dos atos comunicativos, por meio dos desenhos. Forças opostas que, quando combinadas, dão origem a uma nova informação, como também da tradução da palavra e do texto.

O conceito de Simetria, dentro de um padrão dinérgico traduz-se em dois sentidos. O primeiro é o simétrico, que denota uma concordância das partes que integram uma unidade, a harmonia das plantas e a perfeição métrica de representação. O segundo pode-se associar a imagem de uma balança: simetria bilateral, um conceito absolutamente preciso e estritamente geométrico. Ainda segundo Doczi (1990, p.17), o "sentido da simetria é a ideia pela qual o homem tem tentado compreender e criar a ordem, a beleza e a perfeição, através dos tempos".

Regidas pelas leis matemáticas da natureza, na filosofia e na arte, a simetria tem seus registros históricos na Suméria, Bizantina e Pérsia. As figuras são representadas em simetria bilateral ou heráldica e rotacional. Mesmo em desenhos assimétricos, a simetria é sentida como força estética e não formal. O Automorfismo é chamado pelos matemáticos como um conceito geométrico de similaridade; uma transformação em que levam, no mesmo espaço, duas figuras congruentes em outras duas também congruentes. No alfabeto latino as vogais maiúsculas são simétricas, menos a letra E em uma leitura vertical, mas horizontalmente sua estrutura é simétrica, bem como muitas consoantes. A figura 5 ilustra esta análise com uma fonte sem serifa da família Franklin Gothic maiúscula do alfabeto dividido em vogais e consoantes. Todas as letras são partes de um equilíbrio simétrico e assimétrico, derivados da evolução de diversas combinações de linhas, traços, desenhos e figuras repetidas.

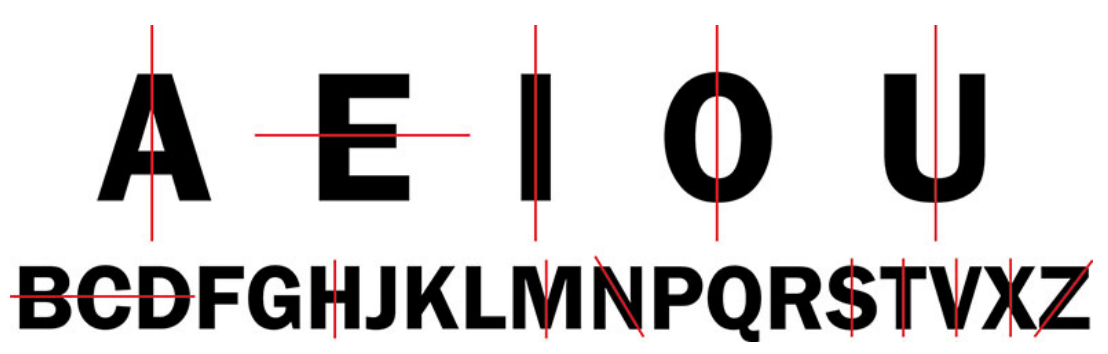

Figura 5 - Simetria no alfabeto latino da família Franklin Gothic maiúsculo. Fonte: Elaborado pelo autor

A natureza expressa representações significativas de simetria para sua organização geral. $O$ equilíbrio e a rotação de forças somente são prováveis com a simetria. O corpo humano como todos os vertebrados são dotados basicamente de 
simetria bilateral, isto é, a esquerda e a direita são da mesma essência. No design e na produção tipográfica, a simetria é sinônimo de beleza, estética e equilíbrio. Simetria é uma das técnicas visuais propostas por Dondis (2003) que descreve as polaridades como uma grande variedade de meio para a expressão do conteúdo e do sentido. Como técnica visual primária de polaridades a simetria, e sua manifestação inversa, a assimetria, têm papel importante na composição e estão presentes em outras técnicas como complementares, buscando a velocidade e a imediatez de um canal de informação. Dondis (2003, p.142) relata que:

\begin{abstract}
Simetria é o equilíbrio axial. É uma formulação totalmente resolvida, em que cada unidade situada de um lado de uma linha central é rigorosamente repetida do outro lado. Trata-se de uma concepção visual caracterizada pela lógica e pela simplicidade absolutas, mas que pode tornar-se estática, e mesmo enfadonha. Os gregos veriam a assimetria um equilíbrio precário, mas que, na verdade, o equilíbrio pode ser obtido através da variação de elementos e posições, que equivale a um equilíbrio de compensação.
\end{abstract}

O significado das mensagens visuais não somente se encontra nos efeitos cumulativos dos elementos básicos do produto tipográfico, mas também no processo perceptivo e experimentado universalmente pelo organismo humano. Ao combinar e manipular os tipos, o designer potencializa o significado gerado pela palavra por meio das simetrias e de um padrão dinérgico.

Um outro aspecto, é que uma mensagem visual tipográfica deve ser criada ou articulada para servir a um propósito funcional. Por meio de uma técnica a mensagem tem contato direto com o usuário, refletindo emoções e sentimentos que vão além do meio e do significado essencial consciente, para chegar ao inconsciente (DONDIS, 2003). Entretanto, levar em consideração o grau de interpretação do usuário leitor pela retórica na utilização de padrões visuais e tipos, envolve o emprego de uma linguagem que ofereça uma qualidade dinâmica e cognitiva capaz de despertar forças psicofísicas que desencadearão acontecimentos e ocorrências visuais veiculadas. 0 leitor passa a interagir tomado pelo sentido definido em formas, símbolos e cores, na utilização ou criação do padrão tipográfico para a mensagem transmitida.

Padrões visuais e geometria são inerentes aos princípios do design gráfico contemporâneo, que quando colocados em prática, melhoram a performance da tipografia na efetivação do consumo e na satisfação do uso. Os diferentes caminhos utilizados na obtenção de resultados positivos, partem de forças compositivas já experimentadas e estruturadas por áreas de conhecimento e que oferecem instrumentação e subsídios metodológicos projetuais ao designer, para intensificar a geração do sentido do tipo em sua representação gráfica.

\title{
2.3 Gestalt e Tipografia
}

A principal característica do design como área de conhecimento, é sua visão multifacetada da realidade, ou seja, a capacidade de estabelecer relações com diferentes conceitos produtivos e geradores de informação. É nestas relações que o designer age de maneira dinérgica com a mensagem, em outras palavras, ele utiliza-se de diversas e diferentes fontes de conhecimento e recursos visuais para gerar um significado gráfico novo.

O pensamento gestaltiano oferece ao design e a criação tipográfica, além de explicações de fenômenos cognitivos da expressão verbal ou visual, também uma lista 
de elementos básicos de uma mensagem e que constituem a substância básica daquilo que se vê. O termo Gestalt foi cunhado na Escola de Psicologia Experimental designada para atuar na teoria da forma e da expressão, em 1910, na Alemanha. Sua origem contribuiu com estudos científicos sobre percepção, linguagem, memória e motivação e possibilitaram esclarecer os propósitos físicos que reagem a atenção do indivíduo ou grupo social. A teoria da Gestalt, de acordo com Gomes Filho (2004, p.18), "respondeu perguntas com experimentos e pesquisas exploratórias sobre estímulo visual e cognitivo provocados no homem. Desta maneira, contribuiu com estudos da percepção, linguagem, memória, motivação e conduta na relação entre sujeito/objeto". Ainda nos dizeres de Gomes Filho (2004), as teorias gestaltianas opõem-se ao subjetivismo e apoiam-se na fisiologia do sistema nervoso central e na capacidade física dos sentidos e da percepção.

Num sentido mais amplo, Gestalt significa uma interação de "partes" em oposição a soma do "todo". O termo, que deu o nome a Escola, geralmente é traduzido como estrutura, figura e forma. A teoria apresenta fundamentos sobre o fenômeno da percepção visual com sistemáticas pesquisas experimentais, levando em consideração o processo cerebral (auto-regulagem e estabilidade) e o processo independente (inerente a vontade, ou ao aprendizado).

Os pesquisadores Köhler e Adams (apud HENLE, 1961) concluem que o primeiro momento da observação de uma informação visual é de forma unificada, que num segundo momento, segundo os autores (apud HENLE, 1961), o olho humano identifica os componentes individuais e básicos através do estímulo visual e de suas relações estruturais entre forma e conteúdo. No artigo intitulado Percepção e Atenção (apud HENLE, 1961), Köhler e Adams afirmam que os procedimentos de leitura determinados por formas regulares são lidos com maior dinamismo do que de formas irregulares. Isso porque há a acomodação dos olhos em um eixo horizontal e vertical no ato da leitura, segundo os autores esse eixo poderá correr a mensagem na busca de mais informações.

O principal fundamento gestaltiano descrito por Dondis (2003, p. 30 a 37):

no processo de composição e leitura visual é o equilíbrio que produz uma
certeza e firmeza pelo fato de existir um ajustamento entre as partes
horizontal e vertical num eixo central. Como referência visual o equilíbrio
estabiliza com simplicidade a coexistência de elementos por ser
tecnicamente calculável.

A autora (DONDIS, 2003) ainda denomina o eixo central como eixo sentido que expressa uma presença invisível, mas preponderante do ato de ver inerente às percepções do homem. Outro fundamento descrito por Dondis (2003) para a composição e leitura de mensagens visuais e dos tipos gráficos é a tensão. Este é um processo de ordenação intuitivo da regularidade ou da ausência dela que para atingir a estabilidade impõe-se um eixo vertical para analisar o equilíbrio e uma base horizontal.

Na teoria da percepção, ainda nos dizeres de Dondis (2003), o valor da tensão para a comunicação é reforçar o significado com um propósito e intenção, sua presença ou ausência é o primeiro fator compositivo na criação de mensagens visuais tipográficas. O equilíbrio e a estabilidade são previsíveis e empalidecem uma mensagem gráfica, diante das polaridades inesperadas causadas pelas tensões. Na psicologia da Gestalt tais opostos são denominados nivelamento e aguçamento. 0 
nivelamento não exige do leitor muito esforço no uso das informações distribuídas visualmente. A reação do observador é imediata ao nivelamento, mas, contudo a mensagem exige esforço na decodificação dos elementos na busca de um equilíbrio invisível inerente aos olhos humanos em uma informação aguçada, aponta Dondis (2003).

Gomes Filho (2004, p. 62) afirma que "contraste começa no nível básico de visão através da presença ou ausência de luz". O autor (GOMES FILHO, 2004) explicita que contraste é o principal responsável pela identificação destas forças e para a formação de unidades visuais. Contraste pode ser obtido pela qualidade da cor, brilho ou forma, como também para a identificação e formação de unidades por pontos, linhas e planos através do fechamento entre as unidades constituídas do objeto observado. Todos os elementos visuais que compõem o produto têm características individuais que podem ser partilhadas ou fragmentadas em unidades informativas. $\mathrm{O}$ que oferece e revela ao leitor do tipo observado, é o significado atribuído e a sua configuração estabelecida no projeto o qual são abordados, avaliados e inseridos recursos técnicos necessários para o sucesso da comunicação.

A Gestalt também explora o contraste como um de seus principais fundamentos, um poderoso instrumento de expressão tipográfica, o meio para intensificar o significado e, portanto, simplificar a informação. O contraste tem a função de racionalizar, explicar e resolver as confusões e necessidades no campo visual, separando e exaltando os elementos básicos da configuração e de relacionamento entre letras e imagens. Como estratégia visual o contraste pode dramatizar o significado do tipo, para torná-lo mais importante e mais dinâmico. Para Dondis (2003) contraste é um caminho fundamental para a clareza do conteúdo entre arte e comunicação. Dondis (2003) divide o contraste em tom, cor, forma e escala. 0 contraste, nessa busca, é a ponte entre a definição e a compreensão das ideias visuais, imagens e sensações tipográficas. O processo perceptivo do homem necessita de estímulos visuais que serão processados pelo cérebro, como a luz que incide na superfície do objeto informação e como as distâncias das partes ou campo visual observado. $O$ contraste pode ser calculado em primeiro e segundo plano considerando a luminosidade. É absoluta a consideração da precisão relativa aos planos varridos pelo olho para depois ser unida no eixo axial, completa Dondis (2003) .

As imagens da figura 6 são exemplos contemporâneos de experimentos tipográficos. Na primeira imagem um pôster para a palavra Aids, do designer Cai Oyafuso (REVISTAARTS COMPUTER BRASIL, 2009), podem-se observar formas abertas e fechadas simples que resultam em relacionamentos entre espaços negativos e positivos. O tipo empregado na imagem é da família bastão, sem serifa e de fácil identificação. Contudo, este trabalho requer do usuário esforço para a leitura. A acuidade visual será o caminho percorrido pelo olho humano e as associações estabelecidas com as letras no isolamento das partes. Esta adaptação ou troca neural entre primeiro plano e fundo através do contraste dos elementos do exemplo, faz surgir desenhos na palavra que reforçam visualmente o significado da mensagem. A criação e expressão gráfica com tipos geram associações que podem ser medidas e calculadas, as interpretações de uma ideia ou sentimento serão inseridas ou retiradas das letras, tornam-se também um trabalho ilustrativo. Os exemplos da figura 5 exemplificam a relação entre processo perceptivo e processo construtivo de imagens. A fusão de diferentes técnicas visuais como o contraste de cor e forma, tom e escala 
podem ser observados no aguçamento informacional proporcionado pelo equilíbrio e repetição de símbolos e sinais através de simetrias e repetições.

Na segunda imagem da figura 6, um projeto da fonte Trick Fun do designer romeno Adrei Robu. Para o designer que entre seus clientes está a Coca-Cola Company, "o tipo ilustrativo funciona em qualquer lugar e em qualquer contexto... ele é muito mais profundo do que uma ilustração ou uma frase isolada" (REVISTA ARTS COMPUTER BRASIL, p. 51). No trabalho do designer apresentado neste estudo a legibilidade foi alcançada pelo movimento e textura do desenho das letras. $\mathrm{Na}$ classificação feita por Thibaudeau, este tipo pertence à família fantasia por estar personalizado e desconstruído visualmente de maneira particular. O processo perceptivo e a compreensão dos caracteres, tornam a leitura irregular e não linear, mas com a segregação dos elementos primários como ponto, linha e plano asseguram a comunicação verbal da mensagem.
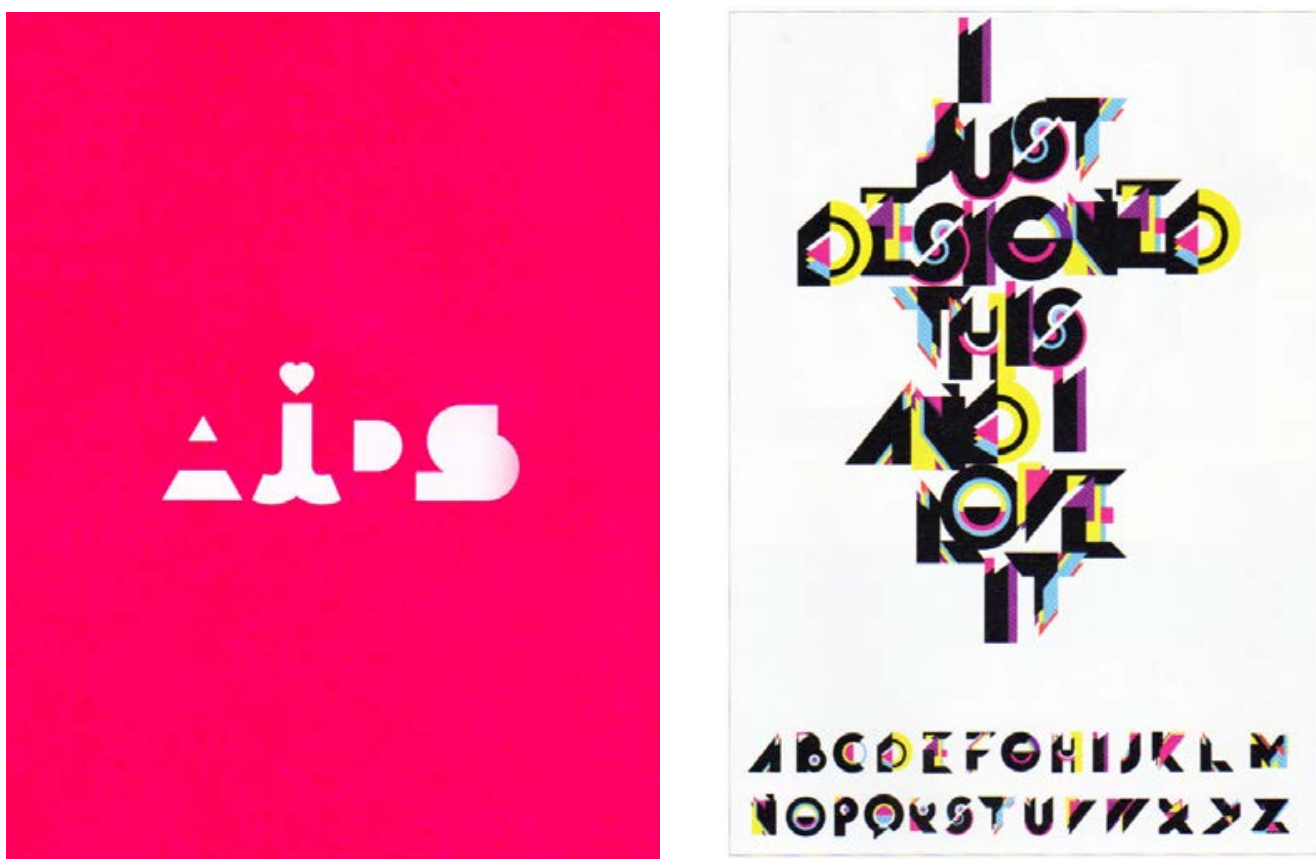

Figura 6 - Na primeira imagem projeto de Caio Oyafuso para uma campanha da Aids e na imagem seguinte, fonte Trick Fun, do designer Andrei Robu.

Fonte: Artes Computer (2009, p. 47 e 51).

Nota-se nas imagens da figura 5 a base geométrica expressada por um eixo sentido central desenhado e projetado para suscitar novos relacionamentos com a mensagem. Na primeira imagem este eixo sentido é forçado pelo ponto, representado pela letra "I" (órgão genital masculino e feminino) gerando o significado de uma relação sexual com um sentido de leitura da palavra AIDS na horizontal. No projeto da segunda imagem percebe-se uma força vertical central construída para identificar os caracteres e facilitar o percurso da leitura da frase.

\section{CONCLUSÃO}

As técnicas gráficas devem ser utilizadas cuidadosamente para a obtenção de resultados satisfatórios na mensagem construída. A tipografia é uma expressão do pensamento ou ideia que poderá ou não ser manipulada, transformada, alterada ou 
acrescida de estímulos visuais nas mãos do designer. De acordo com as necessidades do público leitor, encontradas na pesquisa e observação da história e do uso, percebese que o designer retira informações que servirão como base projetual da criação da letra. Portanto, o design de tipos propõe novos cenários no ambiente cultural da tipografia com técnicas facilitadoras no processo de manipulação da mensagem escrita; propõe novos conceitos e contextualiza a informação no relacionamento entre princípios de leitura da informação e características construtivas da geometria.

O conhecimento teórico-conceitual das relações psíquicas que fundamentam o design gráfico e a criação tipográfica é imprescindível para proceder a construção de mensagens visuais e transformá-las em veículo da informação. Toda e qualquer forma passível de ser lida e interpretada são fundamentais para análise e síntese de organização no desenvolvimento do projeto de um tipo ou família de sinais. A compreensão dos fundamentos da Gestalt e o emprego de técnicas visuais na criação e manipulação de letras, sustentam sua objetividade e efetiva sua leitura. Os processos de comunicação se fortalecem aliados às categorias dos processos perceptivos que estruturam o conteúdo informacional de uma mensagem e estabelece limites conceituais no planejamento gráfico de uma letra. A relação entre tipografia e usuário leitor gera uma situação favorável aos princípios de unificação e segregação, isto é, os tipos seguem o mesmo padrão visual estabelecido para uma leitura contínua e de fácil identificação de acordo com o suporte tecnológico ou objeto midiático proposto. Desta maneira a utilização de elementos, entre formas e cores representados simbolicamente podem ser programados, articulados e distribuídos no tipo, bem como provocar o estímulo visual adequado.

\section{REFERÊNCIAS}

BAER, Lorenzo. Produção Gráfica. São Paulo: SENAC, 1999.

BRIGGS, Asa; BURKE, Peter. Uma História social da mídia: de Gutenberg à Internet. Tradução de Maria Carmelita P. Dias. 2. ed. rev. e ampl. Rio de Janeiro: Zahar, 2006.

CAMARGO, Mário de (org.) Gráfica: arte e indústria no Brasil. 2. ed. São Paulo: Bandeirantes Gráfica, 2003.

DeFLEUR, Melvin; BALL-ROCKEACH, Sandra. Teorias da Comunicação de Massa. Tradução de Octavio Alves Velho. Rio de Janeiro: Jorge Zahar, 1993.

DOCZI, Gyorgy. O Poder dos Limites: Harmonias e Proporções na Natureza, Arte e Arquitetura. Tradução de Maria Helena O. Tricca e Júlia Bárány Bartolomei. São Paulo: Mercuryo, 1990.

DONDIS, Donis A. Sintaxe da Linguagem Visual. Tradução Jeferson Luiz Camargo. 2 Ed. . São Paulo: Martins Fontes, 2003.

FRUTIGER, Adrian. Sinais e Símbolos: Desenho, Projeto e Significado. Tradução de Carina Jannini. São Paulo: Martins Fontes , 1999.

GOMES FILHO, João. Gestalt do objeto: sistema de leitura visual da forma. São Paulo: Escritura Editora, 2004.

HENLE, Mary (org.). Gestalty Psychology. Berkely, University of Califórnia Press, 1961. HERMANN, Weyl. Simetria. Tradução Victor Baranauskas. São Paulo, Edusp, 1997. 
JURY, David. What is typography? Switzerland, UK: Rotovision, 2006.

LUPTON, Ellen. Pensar com Tipos. Tradução de André Stolarski. São Paulo: Cosac Naify, 2006.

NIEMEYER, Lucy. Tipografia: uma apresentação. 4. ed. Rio de Janeiro: 2AB, 2006.

OSTROWER, Fayga. Criatividade e Processos de Criação. São Paulo: Vozes, 1997.

REVISTA ARTS COMPUTER BRASIL. Arte com tipos. São Paulo, ano 2, janeiro 2009.

RIBEIRO, Milton. Planejamento Visual Gráfico. Brasília: Linha Gráfica, 1998. 